\title{
Contribution of Gauripur zamindar Raja Prabhat Chandra Barua: - A historical analysis
}

\author{
Rabindra Das \\ Assistant Professor, Department of History,Bholanath College, Dhubri, India
}

\begin{abstract}
The zamindary of Gauripur situated in the district of Goalpara (undivided), now present district of Dhubri. Gauripur zamindary is larger in size than any other zamindary in Goalpara. The size of zamindary was 355 square miles. It was originated from the Nankar receipt from Mughal Emperor Jahangir. Kabindra Patra was appointed to the post of Naib kanangu of the thana Rangamati, situated near Gauripur. His descendants had enjoyed the office of Kananguship for more than 300 years. The zamindars of Gauripur are mainly feudal in nature. Their main motive was to occupy land and possessed a vast tract of land in the $2^{\text {nd }}$ decade of $17^{\text {th }}$ century. The zamindars of Gauripur were conservative in their outlook but some of the zamindars of Gauripur paid their attention to benevolent public works. Once a time western Assam was more advance than eastern Assam because of the benevolent activities of Gauripur zamindars. Raja Prabhat Chandra Barua was one of the zamindars in Gauripur zamindary who paid attention to develop the society in every sphere. He was an exchequer in the public works, viz. education $52 \%$, hospital 16\%, sadabrata 18\%, donation 12\%, and public health $2 \%$. Thus he contributed in every aspect of society, education, art, culture, economic, and so on for the welfare of the mass people.
\end{abstract}

Keywords: Contribution, Gauripur zamindar, Raja Prabhat Chandra Barua

\section{Introduction}

The Rangamati Baruas who now enjoy a respectable position among the landed magnates in the provinces of Assam in Goalpara district (undivided) and once held in high esteem in the court of Bengal,Mithila and Kamrupa. The rise of the Baruas of Rangamatis or Gauripur can be traced back as far as the $8^{\text {th }}$ centuries. The Gauripur raj estate was situated between 25.58-26.19 west and longitude 85.50-90.60 easts. It has an average elevation of 26 meters. Gauripur is a small beautiful town in the western side of the district head quarter Dhubri. The main town is situated by the river Godadhar on its eastern side, Matiabagh on which the palaced named (Hauakhana) made by the zamindars of Gauripur in the north eastern side.The national high way 31 runs across the town. The Gauripur raj Zamindars belongs to seven paraganas.viz Ghurla,zamira,Maqrampur,GolaAlamganj,Nowabad future,kalumalupara and ourangabad . One partion of Tariapara gaon also included in Gauripur Zamindaries. Besides some lakhiraj lands of Bijni Zamindaries also i ncluded in Gauripu Zamindaries. The size of Gauripur Zamindaries was 356 square miles. The gauripur raj was situated in the district of Goalpara, present Dhubri district of Assam.

The history of Gauripur zamindar is one of the important parts of local history. Very few people know about the history of Gauripur zamindars and their contribution or patronization towards development of society. Very limited research works were done to explore the history of Goalpara and Gauripur zamindary. Once a time western Assam was more advance than eastern Assam because of the benevolent activities of Gauripur zamindars. The district of Goalpara was under the perview of western Assam and Rangamati, near Gauripur was main centre of western Assam during the Mughal dominance of Western Assam. The activities of zamindars not only fixed at their respective boundary but also other parts of Assam. They became the leaders in socio-cultural, political and economic development and provide outstanding contribution towards development of Assam during British rule with support of Government. Most people know Raja Prabhat Chandra Barua as a zamindar, not aware about their developmental activities. In course of time the development of Western Assam became constrained due to negligence of the coordination between Government and zamindars. Besides, the history of Gauripur zamindars has not yet been reflected in the history of Assam and India as a whole. Therefore it is necessary to take step to explore the history of Gauripur zamindars and their contribution to society as a subject of study with observation before they have totally been destroyed by crucial time.

\section{Historical back ground for formation of Goalpara District}

The gauripur raj was situated in the district of Goalpara,present Dhubri district of Assam. It is better to pinpoint the geographical location of Goalpara district to proper understanding the zamindary of Gauripur. Goalpara is the most westernly district of chief commissonership in Assam, occupying the entrance of the Assam valley.It lies along both bank of the Brahmaputra river,extending from 25-27 north latitude, and from 90- 
91 east longitude. It contains an area including the Eastern Duars, which were annexed to the district in 1866,of 4433 square miles, and population of 444,761 souls. The civil station which is also chief town of the district, is Goalpara, situated on the left or south bank of the Brahmaputra river in 26 to25 north latitude and 90 to 40 east longitude. The district of Goalpara is bounded on the north by the Bhutan hill; on the east by the river Manas and Singra; which separate it from the district of Kamrup and by the Garo hill; and on the west by the Sankosh river, which separates it from the Bengal district of Jalpaiguri; by the tributary state of Koch behar and the Bengal district of Rangpur. The Eastern duars was annexed to the district from Bhutan in 1868 and 1869 and the permanent settlement was effected in 1874 and 1875 by the second revenue survey. The Goalpara district has never been a separate political entity under its own kings. It was originally included in the ancient Hindu kingdom of Kamrupa, mentioned in the Mahabharata and some time part of North East Bengal. Goalpara is said to have been conquered, first by the Sen Dynasty and then by the Pal kings of Bengal. In the $15^{\text {th }}$ century the district was included in the dominions of Khyen princes, whose capital was Kamatapur, the modern Lal Bazar in the Koch Behar state. Later it was occupied by the Muhammadans in 1498 A.D. A few years afterwards it passed into the hands of the Koch Kings who established their capital in Koch behar. In 1580 the Koch kingdom was divided and the country east of the Sankosh River which included Goalpara, Kamrup and Darang was surrendered to Raghu Rai, the nephew of Naranarayan. While the territory that lay west of that river was reserved for the son of that Prince.

Goalpara went under the Mughal administration in the middle of the $17^{\text {th }}$ century, and formed the eastern part of the Mughal Empire till with the rest of Bengal, it was ceded to the British by the Emperors Farman of the $12^{\text {th }}$ August, 1765. Under the Mughals the whole of this border region of Bengal was divided into great estate and were held, for the most part by their original owners, the Zamindars, who were practically independent. As acknowledgement of fealty to the Mughal Emperor, they paid a small tribute to the Muhammedan Faujdar of Rangamati in kind, viz. a certain number of elephants or a small quantity of the precious woods, agars to to support certain garrisons and to contribute to the maintenance of the Dacca artillery park.

When the British obtained the Diwani of Bengal, Bihar and Orissa by virtue of the Farman referred to this region of Goalpara district passed over to the administration of the East India Company. The British also kept it same as before and the British used to accept the tribute they paid to the Mughal Government as land revenue in cash or money payment. From 1765 to 1822 Goalpara estate (Goalpara, Dhubri, Kakrajhar ) formed a part of the permanently settled Rangpur district, known as Rangamati District. Goalpara, as comprised in the permanently settled areas was separated from the district of Rangpur on the basis of Regulation X of 1822 of the Governor General of India. It was mentioned in the preamble II that " the tract of the country now comprised into thana jurisdiction of Rangpur is here by declared separated from the said district and the operation of the rules for the administration of the police and of civil and criminal justice, as well as those for the collection of the land revenues, together with all other rules, contained in the Regulation printed and published in the manner prescribed by Regulation XI-I, 1793 are suspended, and shall cease to have effect there from the that of the proclamation of this Regulation accepted in so far as may be here often provided." A commissioner was appointed for the administration of justice in all matters and in February, $1825 \mathrm{Mr}$ David scott was the first official entrusted with the change.

From 1826 to 1866, Goalpara district, remained a part of Assam by the Bhutan war (1864-1866) a strip of the country, extending from Kamrup on the east and Darjeeling on the west, known as Bhutan Duars was acquired by the British in 1866. The strip was divided in to two districts; the eastern Duars was adjacent to the northern part of the district of Goalpara. In 1867, the Koch behar commissionership was formed and by the provision of Government notification of $3^{\text {rd }}$ December, 1867, the district of Goalpara including the newly created eastern Duars and Garo hills were separated from the province of Assam was placed under Koch behar commissionership. In 1868 of $10^{\text {th }}$ August, the civil and criminal jurisdiction was transferred back again to the judicial commissioner of Assam. In 1874 Assam was made a separate administration and eastern Duars with the tract comprising the thana jurisdiction of Goalpara, Dhubri and Karaibari were again transferred to Assam as Goalpara district. Though for a short period of time Goalpara became part of Bengal by the participation of Bengal in 1905 it was again and final till today became an integral part of Assam province.

\section{The Concept Of Zamindars}

As explained in Merriam Webster zamindar means a collector of the land revenue of a district for the Government during the period of Mughal rule in India and also explained feudal landlords in British India paying the government fixed revenue. The feudal lords of Assam were known as 'Bhuyans' can be ascribed from the view expressed by late Dr. Wise, according to whom the word 'Bhuya' or 'Bhuiya' is a Sanskrit equivalent to Persian word 'Zamindars'. The word 'Bhuyans' means landlords, which is synonymous with the Persian equivalent Zamindar and Sanskrit Bhaumik. Besides in an explanation 'zamindars' means an official in 
pre-colonial India assigned to collect the land taxes of his district. A landholder in British colonial India was responsible for collecting and paying taxes to the Government on the land, under his jurisdiction.

\section{Genology of Gauripur zamindars}

According to local sources one Narhari Rai is said to be the ancestor of Gauripur Raj family. Bethera inTirhut of Mozaffarpur was his resident. Eventually Viswa he left his village and joined at service of Koch Kingdom during the rule of singha in early $16^{\text {th }}$ century. He assumed the title Barua instead of Rai for which his descendants were known as Barua. His grandson, Kabindra patra was appointed as the Chief Minister of Koch Kingdom by maharaja Naranarayan. Earlier, kabindra patra was put in charge of guidance of Naranarayan and Chilarai by Viswa singha while they were study at Kashi. However he was later appointed as Chief Minister of Eastern Koch Kingdom by Raghu Narayan. In course of time he received large amount of nankar lands from the Mughal Emperor for his service as kanango, which was considered as the foundation of the Gauripur estate.

Kabindra patra was succeeded by his son Kabishekhar to the post of kanango, who received two sanads, issued by the Mughal Emperor Jahangir in 1622 and 1635 and was granted 9020 bighas of nankar lands .Kabisehkhar was succeeded by his son Kabiratna. During the period of Pratap Chandra Barua zamindary head quarter was shifted from Rangamati to Gauripur in 1860. Pratap Chandra died in 1880 leaving no child for which his wife Rani Bhabani priya adopted a son, named Prabhat Chandra Barua and ran the administration in the name of her minor adopted son, until 1896. Raja Prabhat Chandra Barua assumed the responsibility of the estate in 1896, which was last zamindar of Gauripur Raj estate. He died in 1940 and estate was place under trustee, according to his will that executed before his death. Prabhat Chandra Barua had two wives, Sarajabala and Saradabala. He had five children from the line of Rani Sarajabala, namely Pramathesh Barua, Prakritish Barua, Raj kumara Nihar bala, Raj kumara Nilima sundari and Raj kumar Pranabesh Chandra Barua. From the line of yonger Rani, he had three sons, viz. Amal Chandra Barua, Ajoy Chandra Barua and Ajit Chandra Barua. Raj kumar Prakritesh Chandra Barua was the executive of trust property of the Gauripur Raj estate.

\section{Benevolent activities of Gauripur Zamindar Raja Prabhat Chandra Barua}

The British colonial power never realized the need to work for the socio-cultural upliftment of the Indian people. Rather, India was neglected in every aspect by the British. Whatever they did in India was, indeed, backed by the interest of their colonial and imperial design. But some of the zamindars, as an important social force, had contributed a lot to the social and cultural changes unleashed in the $19^{\text {th }}$ and $20^{\text {th }}$ century. The zamindars of western Assam were not only the followers of the zamindars of Bengal in the matter of zamindary administration and luxurious style of living but also of benevolent works of public important as well. Though they were fond of luxurious style of living for which they, some time resorted to oppressive measures to exact more and more revenue, it cannot be denied that zamindars of western Assam did not contribute to the sociocultural development of the region. Rather, some of the zamindars of this region were patron of learning, music, literature, drama, and art, handicrafts, besides construction of roads, tanks, temples and foundation of charitable hospitals. It is to be mentioned here that during the last part of $19^{\text {th }}$ and early $20^{\text {th }}$ century a wave of public welfare activities spread through the nation as a result of National awakening and freedom movement, initiated by the natives rulers land lords and even the British government of India.

The Baruas of Rangamati, popularly known as the zamindars of Gauripur, although were craving of acquisition of land, even by any means, which lived a life of luxury and the pomp and the grandeur, in the midst, some of them and members of their family paid their attention to benevolent works of public interest. Raja Prabhat Chandra Barua was one of the examples of benevolent worker.

Raja Prabhat Chandra Barua was a benevolent zamindar who devoted himself more on the public welfare works. He is said to be the architect of modern Gauripur town. Though Gauripur was the creation of Pratap Chandra Barua but the modern infrastructure and beautification were the creation of Raja Prabhat Chandra Barua. He developed it as a model town in western Assam, in the model of Koch Bihar Palace. The present structure of Raj Hawli,Howakhana,shismohal,Tajmohal and Attarokotta were built by Prabhat Chandra Barua which are indeed, beautiful specimen of high architectural development of feudal age. The roads, gardens, and tanks were erected with a view to add its beauty and easy communication. It is said that he built Rajhowli and Hawakhana of Matiabag with Chinese engineer and architect.

To look after the public works, Raja Prabhat Chandra Barua created "public works department" and various schemes of development were adopted. He constructed an embankment on the bank of Lawkhowa River, stretching from Gauripur to Rupsi, to protect Gauripur from its flood. He is also said to have constructed road from Gauripur to Dhapdhepi and Gauripur to Kalahat. According to local sources it was constructed joinly by Raja Prabhat Chandra, and zamindar of Rupsi. He also erected tanks and deep wells for drinking water. The famous Mahamaya tank of Gauripur is one of the examples of his public works. According to the statement of some senior citizens of Gauripur like Haji Deraj uddin, aged 92 years old, Gias uddin Prodhani aged above 90. Raja Prabhat Chandra Barua extended help to some victims at the time of severe earthquake in 1897. 
Raja Prabhat Chandra Barua founded a public library at Dhubri which was named as cotton public library, after the name of H.I.S. cotton, then chief commissioner of Assam. He was a patron of education and learning and devoted himself for the spread of eductions among his subjects. He established many schools of all categories, such as lower primary, middle and high schools. He also introduced scholarships system to poor meritorious students.

Raja prabhat Chandra Barua bore the full responsibility to publish "social history of Kamrup" in three volumes, written by N.N.Vasu. As a mark of gratitude Vasu dedicated all the volumes of the books to Raja Prabhat Chandra Barua. Vasu has given a genealogy of Gauripur Raj family in this book. Under patronage of Raja prabhat Chandra Barua, "Kayastha samajer etibrita" was reconstructed and published by H.N.Dutta Barua, a book which deals with the history of kayastha of Assam.

Raja prabhat Chandra Barua patronized the publication of two weekly the "Advocate of Assam" edited by Mathuranath Barua in Guwahati and the "Pranthabashi" edited by Gaurinath Shastri. Prabhat Chandra Barua inspired Amrit Bhushan Adhikary for interpretation and explanation of Sonam Ghosa and all expenditure of its publication were born by him. He extended financial assistance to Ramnath Bidya lankar, the well known Sanskrit pandit of Assam for the publication of Sanskrit grammar, which he wrote with a view spread Sanskrit eduction among the kayastha, Raja prabhat Chandra Barua made arrangement to provide them with all round assistance including free food and lodging. He was a patron of Assam state museum and" kamrup Anushandhan samitee" also. A painting press was setup in Nalbari funded by Raja Prabhat Chandra Barua where twenty people worked and their livelihood.

Raja Prabhat Chandra Barua was the patron of music, arts, drama, fine arts, sports, and indigenous culture of western Assam. He was a famous tabalist and wrote a book on tabla called "Tarangani". He loved music from his core of heart for which he often arranged "musical night" in his Raj Hawli, Attarokotta where reputed singers from different parts of India were invited. His musical programmes were attended by the artist and ustads from Kashi, Kanpur, and Delhi. Under his patronage the deshi loka geet was popularized. His incentive and encouragement boosted his granddaughter, Pratima Pandey Barua who subsequently becomes a legend of Goalparia lok sangeet. Jatra parties were imported from Bengal and staged their plays. Prabhat Chandra Barua had deep interest in drama and he provided his son Pramathesh Chandra Barua with favorable environment to become pioneer of the Indian cinema.

Raja Prabhat Chandra Barua sanctioned every year ten percent of his total revenue for public works and amount spent for different heads of public works as below.

Education-------------52\%
Public health---------16\%
Sadabrata------------18\%
Donation------------12\%
Drinking water-------02\%

Raja Prabhat Chandra Barua was a farsighted person who adopted some policies for the spread of education among his subjects. He organized a fund called "Siksha Samiti" with a view to extend financial help to the poor and meritorious students for higher education. A general body of the Sikha Samiti was formed in 1911 with the members of 100 representatives from different places of his estate and Raja himself presided over the meeting of the Siksha Samiti.

Scholarships were given to students of different categories who were poor and meritorious. Generally scholarships were given to post-metric students, reading arts, sciences, medicals, engineers, and students reading in foreign countries. Manabinda Chakravarty, Srinath Chakravarty, Kamakhya Prasad Roy and many others were the worthy example of such students. Lakheswar Barthakur went to japan for studying in agriculture who later on founded a Sugar Mill in Tinsukia.

Rani Sarajabala, the wife of Raja Prabhat Chandra Barua was the architect of the female education in Gauripur. With a view to educate the women Rani Sarojabala opened a private school in Raj hawli. Raja Prabhat Chandra Barua founded a female primary school in Gauripur which was later come to be known as 1475 no. Gauripur girls school, subsequently it was promoted to middle English school for the girl students.

Raja Prabhat Chandra Barua made remarkable contribution to the expansion of modern education in western Assam. He promoted the middle English school founded by his father Pratap Chandra Barua to a high school in 1809 and named it as Pratap Chandra Institution, in memory of his father. He provided free education to the students of distant places. In the report of 1905 B.C. Allen.D.C. Of Goalpara mentions that there are four high schools in the district which are situated at Dhubri, Goalpara, Abhayapuri and Gauripur which are established by the inspiration and funding of Gauripur Zamindar Raja Prabhat Chandra Barua.

\section{Research Methodology}

The said research work is descriptive and field study based. Most of the data collected through field study and fact funding enquiries is also carried out. The data collected from different original texts and 
documents, census report, news papers, Gazetteers relating to the study. The research paper is supported by personal interview of the people of the different culture of the region, personal observation and questionnaires etc. Archaeological evidences, viz. remains of Gauripur Rajbari and any other related to research area are studied and discussed in collaboration with the literary works of the contemporary periods. An empirical study carried out and data collected from the various primary and secondary sources which are studied properly and systematically.

\section{Conclusion}

We have come to the conclusion of our study that originating in feudalism in the middle ages, zamindary system in Goalpara developed as a part and parcel of the Mughal administration and Gauripur Raj estate originated from a nankar grant, which was received by one Kabindra Patra from the Mughal Emperor Jahangir in the first quarter of the $17^{\text {th }}$ century. Most of the ancestors of the Gauripur Raj family were the revenue officials of the Mughal Governments. In fact, all the zamindars of Goalpara were defacto rulers under the Mughals. Thus, they had generally, acquired administrative

Although the zamindars of Gauripur were feudalistic in character, acquisition of land and even by any means, who lived a life of luxury and the pomp and grandeur, yet some of them and members of their family paid attention liberally towards developments of the society. DhirChandra Barua and his wife Tarini priya were going to be patronized and encouraged for development of Sanskrit education by establishing Sanskrit Chatuspathy in 1834 at Rangamati. Again the contribution of Raja Prabhat Chandra Barua towards development of society was distinct and clear. He paid attention towards development of medical facility by establishing an emergency branch in Dhubri Hospital and donated land to Dhubri T.B.Hospital. Even free medical services were provided to his tenants who were very poor and distress people under Gauripur Estate. The salaries of the doctor and staff were borne by the Royal treasure of Gauripur.

Creation of public works departments, construction of roads and embankment, establishment of public library, patronage of education and learning by establishing many schools of all categories, contribution to literature, development of music and culture etc. clearly proved that he was one of the benevolent zamindars who always devoted to do well to the people of his estate and entire development of his estate.

It was founded that Gauripur became the centre of Music, Drama and culture of Western Assam and made splendid contributions to the development of Music, Drama and fine arts, Pramathesh Barua is said to be the pioneer of Hindi cinema and Pratima Pandey Barua has made huge contribution to the cultural development of Assam especially in Goalpariya folk song. These developments are undoubtly results of liberal and creative attitude of the members of the Gauripur Raj family. Last but not least with the remarks of Santa Barman 'of the zamindars of Gauripur Raj family, Raja Kabi shekhar, Raja Prabhat Chandra Barua and his son Pramathesh Barua were the patrons of Arts and literature.'

\section{Reference:}

[1] Guha, Amalendu, Jamindarkalin Goalpara jilar artha-samajik awastha-ati oitihasik dristipat, Dhubri, 1984

[2] Barman Santa, zamindari system in Assam during British Rule, (A case study of Goalpara District), spectrum publications, Guwahati-1994

[3] Barman, Santa, Goalparar jana itihas, Gawhati, 2009

[4] K.C.Amanatulla Ahmed, Koch Biharer itihas, Modern Book agency, Calcutta, 2001

[5] Basu, N.N., The social history of kamrupa, vol-II, III, New Delhi, 1983

[6] Sarma, Sibananda, Goalparar itihas, Bilasipara, 1976

[7] Das, Dhiren, O mar hastir kaina re, Gauripur, 1994

[8] Smriti Gantha, Asam Sahitya sabha, Bilasipara, 1997

[9] Souvenir, Brahmaputra Beckons, $2^{\text {nd }}$ international conference on Brahmaputra civilization, Goalpara, 2005

[10] Smriti Gantha, Pramathian, Gauripur, 2011 